GA-A23998

\title{
EDGE PLASMA EFFECTS IN DIII-D IMPURITY SEEDED DISCHARGES
}

\author{
by \\ G.L. JACKSON, J.A. BOEDO, C.J. LASNIER, A.W. LEONARD, \\ G.R. MCKEE, M. MURAKAMI, M.R. WADE, J.G. WATKINS, W.P. WEST, \\ and D.G. WHYTE
}




\section{DISCLAIMER}

This report was prepared as an account of work sponsored by an agency of the United States Government. Neither the United States Government nor any agency thereof, nor any of their employees, makes any warranty, express or implied, or assumes any legal liability or responsibility for the accuracy, completeness, or usefulness of any information, apparatus, product, or process disclosed, or represents that its use would not infringe privately owned rights. Reference herein to any specific commercial product, process, or service by trade name, trademark, manufacturer, or otherwise, does not necessarily constitute or imply its endorsement, recommendation, or favoring by the United States Government or any agency thereof. The views and opinions of authors expressed herein do not necessarily state or reflect those of the United States Government or any agency thereof. 


\title{
EDGE PLASMA EFFECTS IN DIII-D IMPURITY SEEDED DISCHARGES
}

\author{
by

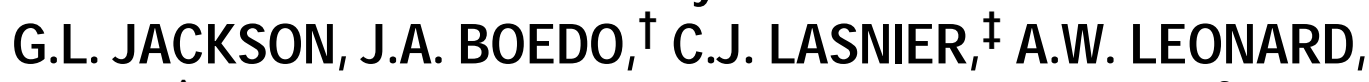 \\ and D.G. WHYTE† \\ tUniversity of California, San Diego \\ ‡Lawrence Livermore National Laboratory \\ $\checkmark$ University of Wisconsin, Madison \\ $\triangle$ Oak Ridge National Laboratory \\ ESandia National Laboratories
} G.R. MCKEE, $\diamond$ M. MURAKAMI, $\triangle$ M.R. WADE, $\Delta$ J.G. WATKINS,£ W.P. WEST,

This is a preprint of a paper presented at the 15th International Conference on Plasma Surface Interactions in Controlled Fusion Devices, May 27-31, 2002, in Gifu, Japan, and to be published in the Proceedings.

Work supported by

the U.S. Department of Energy

under Contracts DE-AC03-99ER54463 W-7405-ENG-48, DE-AC05-00OR22725, DE-AC04-94-AL85000, and Grants DE-FG03-95ER54294, DE-FG03-96ER54373

GA PROJECT 30033

JUNE 2002 


\begin{abstract}
DIII-D, ELMing H-mode radiating mantle discharges have been obtained with electron density near the Greenwald density limit and a large fraction of the input power radiated inside the last closed flux surface, significantly reducing peak divertor heat fluxes. In these "puff and pump" discharges, the introduction of argon reduces particle flux to divertor tiles by a factor of 4 while peak heat flux is half of the no impurity value, suggesting that impurity seeding may be a useful control tool to reduce wall heat and particle fluxes in fusion reactors. A robust $\mathrm{H}$-mode transport barrier is maintained and there is little change in the ELM energy or in the ELM frequency.
\end{abstract}




\section{INTRODUCTION}

Impurity seeded discharges with confinement enhancements comparable to $\mathrm{H}$-mode and reduced peak heat flux to plasma facing components have been observed in many devices [1-4], and these types of discharges may make an attractive fusion reactor scenario. In DIII-D, ELMing $\mathrm{H}$-mode radiating mantle discharges have been obtained with electron density near the Greenwald density limit [5] and a large fraction of the input power radiated inside the last closed flux surface, significantly reducing peak divertor heat fluxes [6]. There is a wide range of operating parameters up to these highest values where good confinement and high density is maintained while heat and particle fluxes to plasma facing surfaces are reduced. This wide parameter range suggests that impurity injection may be tailored to the specific operating requirements of future fusion reactors and, in particular, might be a useful tool in controlling and reducing peak heat and particle wall fluxes.

In this paper we will examine a series of DIII-D ELMing $\mathrm{H}$-mode discharges where discharge conditions were held constant as impurity gas flow, in this case argon, was increased. The temporal characteristics of a typical discharge is shown in Fig. 1. These discharges were accompanied by a high deuterium gas flow from the top of the tokamak, creating a flow towards the lower single-null divertor which is pumped by a toroidally continuous liquid helium cryopump and this technique is call "puff and pump" [7]. Such discharges are useful in examining the reductions of wall fluxes as argon flow is increased. In addition we will discuss the edge effects of other discharges at higher argon flow rates and lower auxiliary power where the highest values of density and core radiation were observed after a "spontaneous transition," described in Ref. [6]. In the following discussion we will define mantle radiation, $\mathrm{P}_{\text {mantle, (measured by the } 48 \text { channel }}$

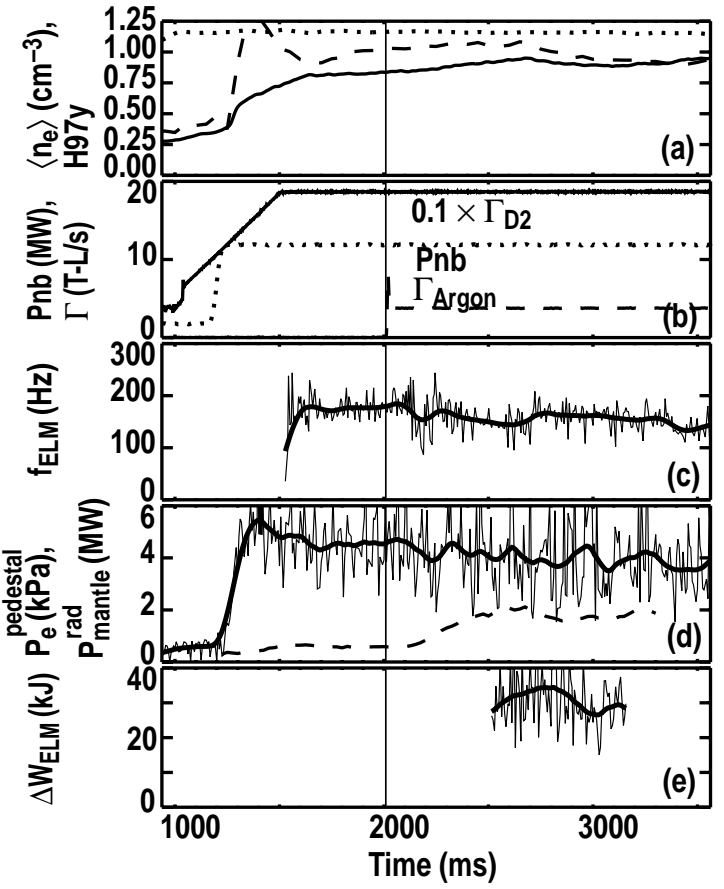

Fig. 1. Temporal characteristics of a typical puff and pump argon seeded discharge (\#95892): H97y (dashed line), $\bar{n}_{e, G W}$ (dotted line) and $\bar{n}_{e}(a), \Gamma_{D 2}$ (solid line), $\Gamma_{A r}$ (dashed line), and $P_{n b}(b), E L M$ frequency (c), edge electron pedestal pressure (solid line) and mantle radiated power (dashed line) (d), and ELM energy loss $(e)$. Solid thick lines in (c), (d), and (e) represent a $100 \mathrm{~ms}$ average to show trends after argon injection. Vertical line shows the start of argon injection. Discharge conditions are: $P_{n b}=12 \mathrm{MW}, I_{p}=1.3 \mathrm{MA}$, $B_{t}=2.1$ T, and $q 95=4.0$. 
bolometer array [8]) as radiation occurring in the region $0.5<\rho<1$, where $\rho$ is the normalized plasma radius. 


\section{EDGE EFFECTS WITH ARGON SEEDING}

An example of the temporal evolution of a typical argon seeded discharge is shown in Fig. 1. A high deuterium gas flow, 190 Torr- $\ell / s$, is established and beam power is held fixed, Fig. 1(b). From 1.5 to $2.0 \mathrm{~s}$ only deuterium is puffed and then at $2.0 \mathrm{~s}$ a constant argon flow is added [Fig. 1(b)]. After argon injection, $\mathrm{H}$-mode confinement is maintained and there are only small decreases in ELM frequency [Fig. 1(c)]. In addition edge electron pedestal pressure, $\mathrm{P}_{\mathrm{e} \text {,ped, }}$ [Fig. 1(d)] only declines slightly indicating that a strong $\mathrm{H}$-mode transport barrier is still maintained as mantle radiation increases four-fold to $1.8 \mathrm{MW}$ [Fig. 1(d)]. Even in similar discharges at higher values of $\mathrm{P}_{\text {mantle }}$ and lower input power, $\mathrm{P}_{\mathrm{e}}$,ped does not decrease appreciably after argon injection (not shown). The energy loss per ELM is shown in Fig. 1(e). Fast Mirnov probe data is integrated, allowing EFIT calculations with $0.5 \mathrm{~ms}$ time resolution which is sufficient to calculate the change in plasma stored energy, $\Delta \mathrm{W}_{\mathrm{MHD}}$, after an ELM.

Although a strong $\mathrm{H}$-mode transport barrier is maintained with argon injection and there is little change in the energy loss per ELM, particle fluxes to the divertor wall tiles decrease markedly, (Fig. 2). The ion saturation current, measured by a Langmuir divertor tile probe [9] at the outer strike point is plotted as a function of time and shows a prompt drop after impurity injection begins. The magnitude of this change is greater as the argon flow is increased, and saturates for flow rates above 3 Torr $-\ell / s$. Other Langmuir tile probes also show reductions in ion saturation current after impurity injection.

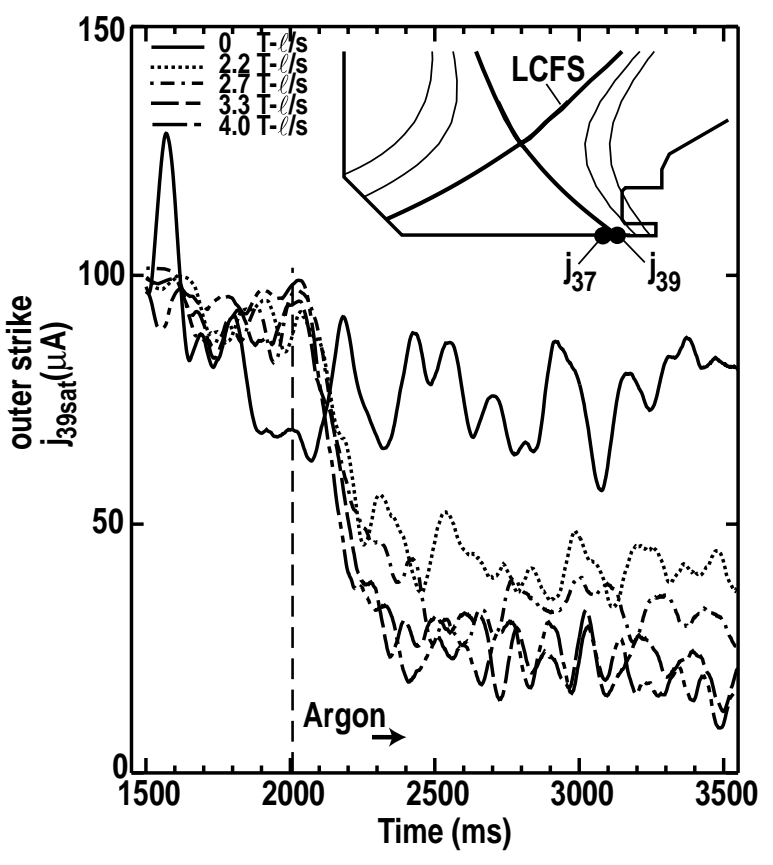

The ion saturation current shown in Fig. 2 represents an average including both ELMs and periods between ELMs. Of more impor-

Fig. 2. Langmuir probe ion saturation current at the outer strike point, j39sat, for 5 discharges (\#95887-90, 92) with varying amounts of argon flow. Discharge conditions are given in Fig. 1 . tance for fusion reactors are peak particle and heat fluxes since these can determine erosion and hence the lifetime of plasma facing components. A relative estimate of the peak particle fluxes can be obtained by correlating measurement times where $j_{\text {sat }}$ (determined by the swept probe voltage) coincides with an ELM and this is plotted in Fig. 3. There is a reduction in the average ion saturation current, and hence particle flux during an ELM, for values of argon flow of 
4 Torr- $\ell / \mathrm{s}$. The ion saturation current is normalized to a previous phase with deuterium only. Note that this is only a relative measurement since the peak ion saturation current, which occurs near the outer strike point, could not be measured directly due to probe saturation and thus an adjacent probe, $\mathrm{j}_{37}$, was used to estimate the reduction in

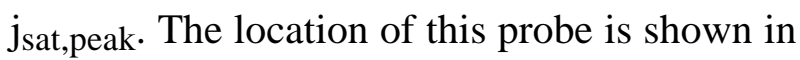
the inset in Fig. 2.

Peak heat flux, measured by an IR camera [10], also decreases after argon injection (Fig. 4). At the highest argon flow rate, a reduction of a factor of 2 is observed near the outer strike point, and a near complete suppression of heat flow is observed at the inner strike point.

Note that an occluded view during these puff and pump experiments does not allow a quantitative measurement of the outer peak heat flux, although the relative change can be inferred from the profiles shown in Fig. 4.

The method of determining the energy loss per ELM was described previously and shown in Fig. 1. The average energy loss per ELM, normalized to the edge pedestal energy, is

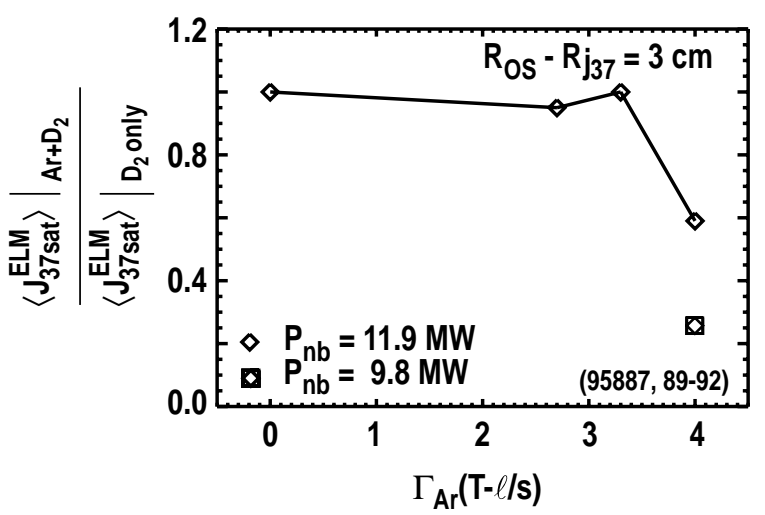

Fig. 3. Ion saturation current with argon injection during ELM events is averaged from 2.5 to $3.4 \mathrm{~s}$ and normalized to an earlier phase with deuterium injection only. A Langmuir probe inboard of the outer strike point, shown in the inset in Fig. 2, is used due to saturation of the probe at the outer strike point.

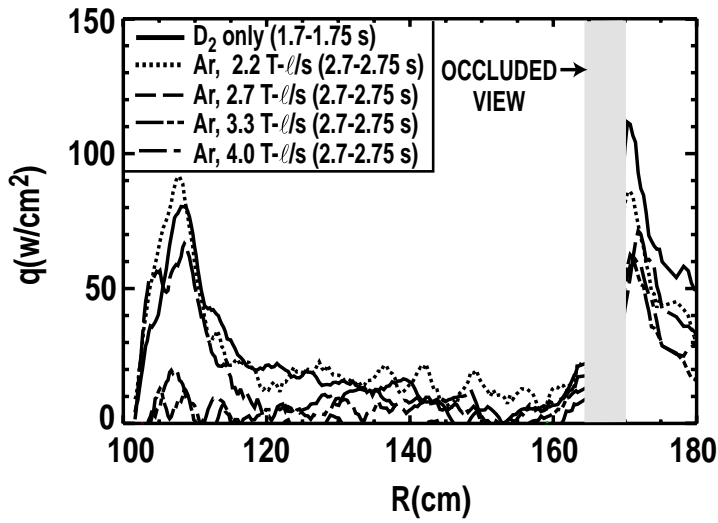

Fig. 4. Profiles of peak heat flux to the divertor tiles as a function of major radius for 4 discharges with varying amounts of argon flow. A deuterium only profile represents an average of these 4 discharges from 1.7 to $1.75 \mathrm{~s}$, before argon injection. Discharge conditions are given in Fig. 1. shown in Fig. 5(a). Pedestal energy is defined using the Fishpool formulation [11] as

$$
\mathrm{W}_{\text {ped }}=2 \times \mathrm{n}_{\mathrm{e}, \text { ped }} \times \mathrm{kT}_{\mathrm{e}, \text { ped }} \times \mathrm{V}_{\mathrm{p}}
$$

where $\mathrm{V}_{\mathrm{p}}$ is the plasma volume and the edge pedestal electron temperatures for ions and electrons are assumed equal, $\mathrm{T}_{\mathrm{e} \text {,ped }}=\mathrm{T}_{\mathrm{i} \text {,ped }}$. Average power loss due to ELMs can also be calculated as

$$
\mathrm{P}_{\mathrm{ELM}}=\Delta \mathrm{W} E L M \times \mathrm{f}_{\mathrm{ELM}}
$$


and is plotted in Fig. 5(b). Normalized to input power.

Both ELM energy loss and ELM power show a small increase as argon flow is increased. Over the range shown in Fig. 5 ( 0 to 4 Torr- $\ell / s$ ), $\Delta \mathrm{W}^{E L M} / \mathrm{W}_{\text {ped }}$ increases $43 \%$ and $\mathrm{P}_{\mathrm{ELM}} / \mathrm{P}_{\text {in }}$ exhibits a $25 \%$ increase.

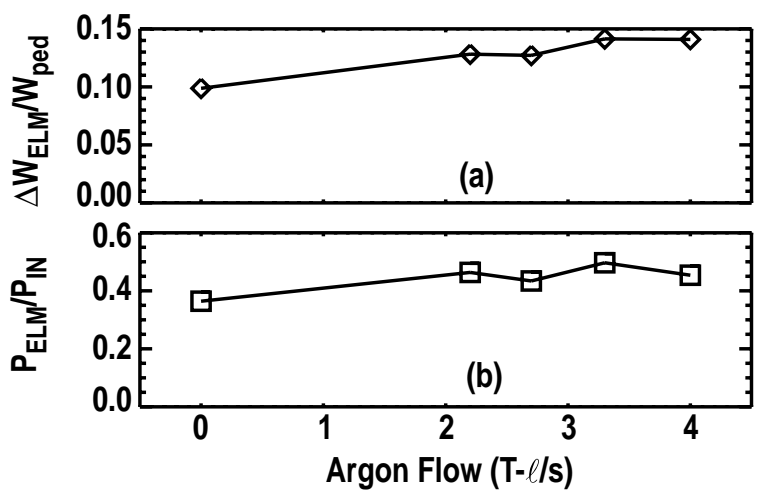

Fig. 5. Energy loss per ELM, normalized to $W_{\text {ped, }}$ is shown as a function of Argon flow, (a). ELM power, defined in Eq. (1) and normalized to input power, is plotted in (b). 


\section{POWER BALANCE}

From the data in Section 2, power flow can be calculated and is summarized in Table 1 for two discharges with different auxiliary heating powers: 12 and $10 \mathrm{MW}$. The latter discharge exhibited a spontaneous transition [6] characterized by a rapid increase in $\mathrm{P}_{\text {mantle }}(0.6$ to 3.2 MW) and a modest increase in density (21\%). Higher core toroidal rotation generally accompanies the spontaneous transition, but the charge exchange neutral beam to make such measurements was not available on this discharge. Note that the IRTV measures total power to the divertor tiles, including a fraction of the ELM power, $\mathrm{c}_{\mathrm{wall}} \times \mathrm{P}_{\mathrm{ELM}}$ and thus summing all of the loss terms in Table 1 does not give an accurate power balance since ELM power reaching the divertor tiles is counted twice. Nevertheless, the changes in power flow with the addition of argon seeding gives a qualitative representation of the effect of impurities on the various loss channels.

Table 1. Power Balance with and without impurity seeding. Input power is positive and loss power is negative. Some PELM data is not available due to limited diagnostic coverage

\begin{tabular}{lcccc}
\hline & $\begin{array}{c}\mathrm{D}_{2} \text { only } \\
(95887)\end{array}$ & $\begin{array}{c}\mathrm{D}_{2}+\mathrm{Ar} \\
(95892)\end{array}$ & $\begin{array}{c}\mathrm{D}_{2} \text { only } \\
(95891, \text { pre-argon })\end{array}$ & $\begin{array}{c}\mathrm{D}_{2}+\mathrm{Ar} \\
(95891)\end{array}$ \\
\hline $\mathrm{P}_{\text {in }}(\mathrm{MW})=\mathrm{P}_{\mathrm{nb}}+\mathrm{P}_{\text {ohmic }}$ & 12.1 & 12.2 & 10.0 & 10.2 \\
$\mathrm{P}_{\text {rad,mantle }}(\mathrm{MW})$ & -0.5 & -2.0 & -0.4 & -3.2 \\
$\mathrm{P}_{\text {rad,div }}(\mathrm{MW})$ & -3.6 & -3.9 & -3.0 & -2.7 \\
$\mathrm{P}_{\text {IR,div }}(\mathrm{MW})$ & -4.4 & -2.3 & -3.0 & -1.4 \\
$\mathrm{P}_{\text {ELM }}(\mathrm{MW})$ & -3.8 & -4.6 & - & -2.4 \\
$\mathbf{P}_{\text {in }}+\mathbf{P}_{\text {loss }}$ & -0.2 & -0.6 & - & +0.5 \\
\hline
\end{tabular}




\section{MIST MODELING}

The MIST code [12] has been used to model radiated power and ion density profiles for all charge states of argon. The total argon radiation as a function of radius is plotted in Fig. 6 at two times: before [Fig. 6(a) and 6(c)] and after [Fig. 6(b) and 6(d)] the spontaneous transition, described above. Note that the radiated power in the SOL decreases at the later time because radiated power is shifted inward as the temperature of the SOL decreases. Impurity radiated power calculated by MIST and radiated power inferred from bolometric measurements agrees within $10 \%$ at the times shown in Fig. 6.
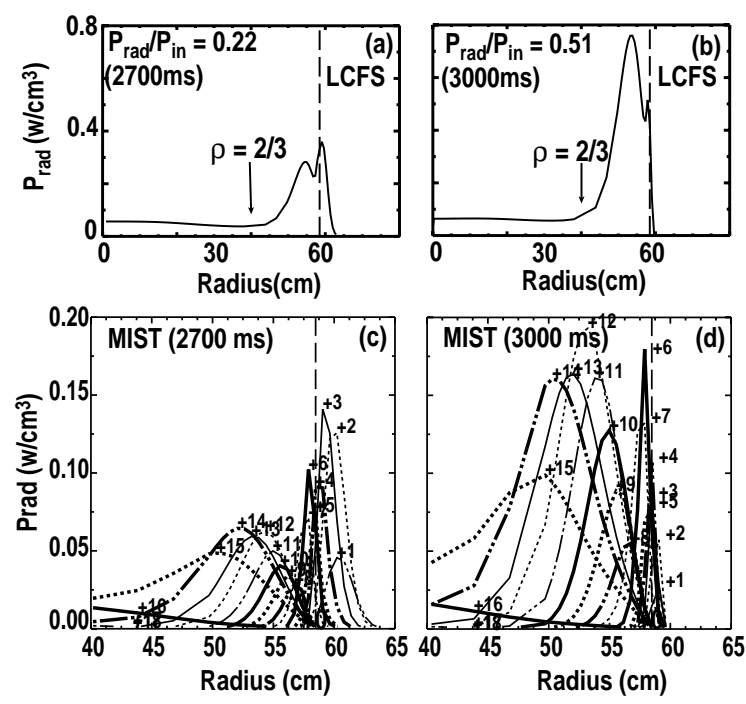

Fig. 6. Profiles of argon impurity radiation at 2 times during an impurity seeded discharge (\#95011) before (a) and $(c)$ and after $(b)$ and $(d)$ a spontaneous transition to higher mantle radiated power. Total argon radiation is shown in $(a)$ and $(b)$ and individual charge states are plotted in $(c)$ and $(d)$. 


\section{DISCUSSION}

The addition of argon seeding to puff and pump deuterium discharges has produced a scenario with good confinement, $\left(\mathrm{H}_{93} \mathrm{y} \sim 1\right)$, high density $\left(\mathrm{f}_{\mathrm{GW}}>0.7\right)$ and with heat and particle fluxes to divertor tiles reduced by factors of 2 to 4 . This makes this scenario a possible control tool to limit wall loading in fusion reactors. Of special importance is the reduction of wall particle fluxes during ELMs (Fig. 3). The normalized ELM energy loss shown in Fig. 5 is consistent with Ref. [13]. However, for the discharges in this paper additional reductions in wall fluxes are achieved with impurity seeding. Further experiments are required to better quantify this ELM particle and heat flux reduction. A new diagnostic, DISRAD [14], can provide faster time resolution to quantify the changes in heat flux during ELM events with impurity seeding. Although we have emphasized edge effects in this paper, we note that there are only modest increases in core impurities in these discharges and central $Z_{\text {eff }}$ actually decreases after a spontaneous transition [6]. The efficacy of using impurity seeding in reactor designs depends critically upon tailoring the impurity radiation profiles to provide the desired reduction in heat and particle fluxes. An example of this was shown in Fig. 6, where SOL radiation dropped as mantle radiation, and hence the SOL electron temperature, changed. Modeling has shown that krypton may be effective for impurity seeding in a reactor [15]. 


\section{REFERENCES}

[1] E.A. Lazarus, J.D. Bell, C.E. Bush, et al., Nucl. Fusion 25, (1985) 135.

[2] A.M. Messiaen, J. Ongena, B. Unterberg, et al., Phys. Plasmas 4, (1997) 1690.

[3] O. Gruber, A. Kallenbach, M. Kaufmann, et al., Phys. Rev. Lett. 74, (1995) 4217.

[4] M. Mori, et al., Nucl. Fusion 28, (1988) 1892.

[5] M. Greenwald, J.L. Terry, S.M. Wolfe, and S. Ejima, Nucl. Fusion 28, (1988) 2199.

[6] G.L. Jackson, M. Murakami, G.R. Mckee, et al., Nucl. Fusion 42, (2002) 28.

[7] M.R. Wade, W.P. West, R.D. Wood, et al., J. Nucl. Mater. 266-299, (1999) 44 .

[8] A.W. Leonard, W.H. Meyer, B.W. Geer, et al., Rev. Sci Instr. 66, (1995) 201.

[9] D. Buchenauer, W.L. Hsu, J.P. Smith, et al., Rev. Sci. Instrum. 61 (1990) 2873.

[10] D.N. Hill, R. Ellis, W. Ferguson, et al., Rev. Sci. Instr. 59, (1988) 1878.

[11] G.M. Fishpool, Nucl. Fusion 38, (1998) 1373.

[12] R.A. Hulse, Nucl. Technol./Fusion 3, (1983) 259.

[13] A.W. Leonard, A. Herrmann, K. Itami, et al., J. Nucl. Mater. 266-299, (1999) 109.

[14] D.S. Gray, S.C. Luckhardt, E. Hollmann, et al., 27th Conf. on Control. Fus. and Plasma Phys., Budapest, 12-16 June 2000, E. Conf. Abs. 24B (2000) 1681.

[15] J. Mandredas, W.M. Stacey, F.A. Kelly, Nucl. Fusion 37, (1997) 1015. 


\section{ACKNOWLEDGMENTS}

Work supported by U.S. Department of Energy under Contracts DE-AC03-99ER54463, W-7405-ENG-48, DE-AC05-00OR22725, DE-AC04-94AL85000, and Grants DE-FG0395ER54294, and DE-FG03-96ER54373. 